\title{
Obtaining Data Linkage Consent for Children: Factors Influencing Outcomes and Potential Biases
}

\section{Tarek Al Baghal}

Institute for Social and Economic Research, University of Essex, Wivenhoe Park, Colchester, Essex CO4 3SQ; e-mail: talbag@essex.ac.uk.

\begin{abstract}
Understanding mechanisms of consent for data linkage has largely focussed on adults, but parents or guardians can also be asked to consent children for which they are responsible. This research uses a large nationally representative survey asking mothers to consent for both themselves and their children for two sets of records. Nearly all mothers give the same consent outcome for all their children. Consent is higher for education records than for health records and higher for mothers than children. Multivariate analyses suggest that minorities are generally less likely to consent, while more trust increases chances of consent. Several survey environment factors are important, with those harder-to-contact less likely to consent, while the presence of others and higher interviewer-respondent rapport lead to a higher chance of consent. These findings suggest potential methodologies to improve consent rates and possibly minimise bias. This is important given significant demographic differences between children across consent outcomes. However, data from a survey of 10-15 year olds in the study shows fewer differences for several important behaviours and attitudes across consent outcomes.
\end{abstract}

Keywords: data linkage, consent for children; longitudinal studies; administrative records; consent bias

\section{Acknowledgments}

This work was supported by the "Understanding Non-response on Understanding Society" project of the National Centre for Research Methods (NCRM) programme [grant number: DU/512589103]. Additional support was received from the Understanding Society project [grant number: ES/K005146/1]. The author would like to thank Jonathan Burton for comments on earlier drafts of the paper and Gundi Knies for insights on consent to data linkage. 


\section{Introduction}

Given the possible benefits, a growing number of survey practitioners see linking administrative data to survey responses as an opportunity to improve data quality while reducing costs and easing interviewer and respondent burden (Korbmacher \& Schroeder 2013; Sakshaug \& Kreuter 2012; Sakshaug, Tutz \& Kreuter 2013; Sala, Burton \& Knies 2012; Sala, Knies \& Burton 2014). Further, data linkage can inform the survey method itself, such as in studies of survey measurement error (Kreuter, Muller \& Trappmann 2010; Olson 2006; Sakshaug, Couper, Ofstedal \& Weir 2012).

Frequently, consent is required to link survey and administrative data. Studies have largely focused on the consent process in surveys for adults; however, parents may also be asked to link their children's administrative records, which may be of particular interest in longitudinal studies. Inclusion of children's records allow for studying changes and outcomes over time for familial units, including intergenerational change (Lightfoot \& Dibben 2013). These linked data may lack generalizability and may be biased, however, if consent is low and/or those who consented are different to those that did not (Sakshaug \& Kreuter 2012; Sakshaug et al. 2012).

Understanding who consents (or not) and possible reasons why are important in determining and potentially minimising the extent of bias. To date, the factors possibly influencing consent for children has not been explored simultaneously and systematically. The present study begins to fill this gap by examining consent for children by extending a framework developed for survey participation and used for adult consent outcomes. The decision to consent to data linkage on behalf of children is examined systematically for two consent requests as well as the consent outcomes for both the mother and child jointly. By supplementing these data with a separate survey administered to 10-15 year olds in the study, this research also begins examination of demographic, behavioural and attitudinal differences 
among those consented for or not, identifying potential biases.

\section{Previous Studies of Data Linkage Consent for Children}

A number of surveys have asked for consent to link children's administrative records (see e.g. Lightfoot \& Dibben 2013). There have been few studies to systematically examine consent for children, however, and these were using focussed populations. McKinney et al. (2005) sought consent from parents who had children admitted into a paediatric intensive care unit. Tate, Calderwood, Dezateaux \& Joshi (2006) asked for birth register and maternity data from a cross-section of mothers of new-borns, but as a single request. Klassen, Lee, Barer, \& Raina (2005) asked for consent both from caregivers and their children, of a cohort born in three hospitals, aged 42 months at the time of the survey.

Consent rates for children in the surveys identified ranged from $43 \%$ (McKinney et al. 2005 ) to $92 \%$ (Tate et al. 2006). Generally, minority groups provided lower consent rates (McKinney et al. 2005; Tate et al. 2006), with some evidence that higher socioeconomic status related to higher rates of consent (Klassen et al. 2005; Tate et al. 2006). These sociodemographic differences are similar to those found in research of adults (see Sakshaug et al. 2012). Examining differences in consent between adults and their children, Klassen et al. (2005) found that higher consent was obtained for children than adults (7.1\% higher). This difference was only found among families with a baby admitted to the neonatal intensive care unit (NICU), however, and the authors speculate that parents may have felt that consent would benefit these less healthy babies more.

\section{A Framework for Understanding Consent}

The identified studies of consent for children have examined feasibility and possible biases based on sociodemographic differences in consent rates. However, there is a growing understanding that a number of factors influence the consent decision beyond respondent 
characteristics. As such it has been suggested that consent decisions may possibly be understood through the Groves \& Couper (1998) framework for understanding survey participation (Korbmacher \& Schroeder 2013). This framework suggests that multiple factors influence the consent decision, including the respondent, the respondent's household environment, the survey environment and the interviewer.

There are several examples of respondent-level factors that may influence consent outcomes. Respondent (e.g. parent) factors have been the most frequently examined in studies of consent for children outcomes in surveys. The factors identified as influential include respondent ethnicity and socioeconomic status (Klassen et al. 2005; McKinney et al. 2005; Tate et al. 2006). Additionally, studies of adult consent decisions find respondents' who express greater trust in people are more likely to consent (Sala et al. 2012), while those expressing concerns about privacy are less likely (Korbmacher \& Schroeder 2013; Sakshaug et al. 2012). Along with trust in other people, those supportive of liberal parties are more likely to consent, suggesting the possible importance of social-orientation (Sala et al. 2012).

Given that the purpose of parental consent in research is protection rather than selfdetermination (e.g. Denham \& Nelson 2002), trust may be even more important in child consent decisions. Although not tested here, views toward protection and self-determination and the consent decision may also be influenced by parental styles. For example, Baumrind (1991) identifies four parenting styles of young children: authoritative, authoritarian, permissive, and rejective-neglecting. She also defines six family types including adolescents: authoritative, democratic, directive, good-enough, nondirective, and unengaged. These typologies have been found to influence numerous outcomes (e.g. Spera 2005; Kawabata, Alink, Tseng, van Ijzendoorn, \& Crick 2011), and may likewise influence parents' decision to link their children's administrative records or not. 
Extending the framework at the respondent-level for the request to link children's records, the parent/responsible adult may also take into consideration specific factors about the child. These include factors that are not necessarily shared with the responsible adult, as is frequently the case with race or household income. A child's health, educational achievement, personality, etc. may all influence the decision of the responsible adult to share the child's records, possibly depending on the records requested. The finding that consent was given to access health records for children admitted to the NICU suggests the influence of such child-record specific factors (Klassen et al. 2005).

Next, the respondent's household environment may also affect consent outcomes, although to date this has not been explored in-depth for child consent outcomes. Generally, those in urban areas respond to surveys less, possibly due to less interpersonal trust or concerns about crime (House and Wolf 1978). In studies of adult consent, Korbmacher and Schroeder (2013) similarly find lower consent rates among those living in urban areas, while Sala et al. (2012) find no differences between those living in London /Southeast England and elsewhere. If urban settings influence interpersonal trust, there could be an important influence on child consent decisions as this trust (or lack thereof) may influence the decisions of responsible adults (Lightfoot \& Dibben 2013). Having children in the household environment may itself influence consent, as households with children are identified as being more likely to consent relative to single resident households (Jenkins et al. 2006).

The survey environment is another potentially important factor in consent outcomes, but has yet to be examined in the context of consent for children. In studies of adults, harderto-contact respondents are also less likely to consent to link their administrative records (Sakshaug et al. 2012; Sala et al. 2012). Conversely, greater levels of apparent interviewerrespondent rapport boost consents rates (Jenkins et al. 2006). Rapport can encourage consent by increasing respondent motivation and the desire to gain interviewer approval (Cannell, 
Miller and Oksenberg 1981; Dijkstra 1987). This rapport is likely to influence child consent outcomes as well. Findings in clinical studies suggest higher consent rates for children when the person presenting the study (the interviewer in a survey context) is perceived as friendly, professional, and makes respondents feel comfortable (Hoberman et al. 2013; Tait, VoepelLewis, and Malviya 2003).

Finally, the effect of interviewer characteristics may affect outcomes, but studies of adult consent decisions find mixed results. For example, Korbmacher \& Schroeder (2013) find effects of interviewer age and experience, with older and more experienced having greater success, while Sakshaug et al. (2012) find no interviewer effects. Interviewer sex has not been identified as an important factor for consent, but studies examining survey participation find when both the interviewer and respondent are female, survey cooperation is higher (Durrant et al. 2010). Interviewers' experience with the survey has significantly improved consent in some studies (Sala et al. 2012), but not in others (Sakshaug et al. 2012). For child consent, this experience overall and within the study may be important as it may influence the explanation of the study. Clinical studies suggest greater child consent rates when the person presenting the study was perceived to have explained the study well (Hoberman et al. 2013).

\section{Data and Methods}

\section{Sample}

Understanding Society: The United Kingdom Longitudinal Household Study (University of Essex 2012) is a large ( 40,000 households at Wave 1) annual longitudinal survey that collects data about a variety of issues in order to understand long-term effects of social and economic change in the UK. Each wave of the survey is conducted over a two-year period. The first wave of the survey was conducted over 2009 and 2010. 
Two samples are used from the first wave of Understanding Society, a large General Population Sample (GP) plus the Ethnic Minority Boost (EMB). The EMB sample was designed to provide at least 1,000 interviewed adults from each of five groups: Indian, Pakistani, Bangladeshi, Caribbean, and Africans. Understanding Society employs a complex survey sample, employing a stratified-clustered design selected through probability proportionate to size (PPS) methods. More information of the sample design can be found in Lynn (2009) and in Knies (2014).

The survey was conducted using face-to-face computer-assisted personal interviewing (CAPI). An interviewer had to make a minimum of six calls before a household could be classified as a non-contact, including calls at evenings and weekends (interviewers could do more than six). Interviews were attempted for all members of the household aged 16 and over. The household response rate for the GP sample (including households providing at least one survey) is $57.3 \%$ (AAPOR RR3). The individual response rate conditional on household participation is $81.8 \%$. The EMB sample had lower response rates: a $39.9 \%$ household response rate and a $72.4 \%$ conditional individual response rate.

\section{The Consent Request}

At the end of the survey, respondents were told the study would like to link administrative records to their survey responses. All respondents were first asked about linking their own health records from the National Health Service (NHS). Respondents were told:

Finally, we would like to add some information from administrative health records to the answers you have given. This leaflet gives you information about what we would like to do. Please read it, ask me any questions and sign the form if you are happy for us to do this. 
They were then given the leaflet and the consent form to sign. This request was immediately followed by the consent request for their children's NHS records along with a consent form; by saying "We would also like to add further information on your child's health and use of health services. Could you read through this form and sign it if you wish to give permission." Due to the nature of the records maintained at the administrative level, education record-linkage consent was then asked to those born after 1981 and attended school in the UK by saying, "We would also like to add information from your education records. Here is a permission form and information leaflet. Please read this, ask me any questions and sign the form if you are happy for us to do this." Regardless of whether they were asked to consent for linking their own education records, adults responsible for children aged 4-15 years old were asked for consent to link their children's education records to the survey: "We would also like to add further information on your child's education. Here is a permission form and information leaflet. Please read this, ask me any questions, and sign the form if you wish to give permission." Separate forms were handed out for health and education, with separate forms for adults and children. ${ }^{1}$

For requests to link children's records, one adult in the household was deemed responsible. If the mother was part of the household, she was listed as responsible. If she was not, then the father was listed, if neither, then the closest adult relation was listed. The vast majority of consenting adults (95.6\%) was the biological mother. Biological fathers made up $3.0 \%$, with the remaining $1.4 \%$ of consenting adults includes adoptive mothers, grandmothers, adoptive fathers, grandfathers, stepmothers, stepfathers, older siblings, and other caretakers. Given that all other adults were asked for consent only in cases when the biological mother was not available, sex effects may be confounded with effects relating to

\footnotetext{
${ }^{1}$ Information leaflets and consent forms can be found at https://www.understandingsociety.ac.uk/documentation/mainstage/fieldwork-documents
} 
the absence of the mother. Due to this possible confounding and that most responsible adults were biological mothers, analyses are restricted to these mothers to ensure comparability.

Consent to link records was asked for 14,570 children under the age of 15 from 8,309 mothers. However, almost every mother either consented for all of their children or none of their children for a given request. Only 37 adults, representing 96 children, gave different consent decisions across their children for at least one of the record requests. All of these inconsistencies occurred for only one child in the family, regardless of total number of children. That is, in instances of three or more children, 1 child had one outcome and the others all had the other outcome. Of the 37 adults, 22 were inconsistent for health records only, 9 for education records only, and 6 inconsistent to both.

This finding suggests that child-level factors may not be as influential as respondent factors, at least in this particular case. Given the overall high-level of consistency and the apparent impact of respondent but not child-level factors suggests that the decisions to consent for any number children are effectively a single one. While those giving inconsistent decisions are an interesting subgroup, the number is too small to reliably examine child-level factors, and these are set aside in the following analysis. Dropping the small number of inconsistent cases leaves 14,493 children and 8,272 mothers, leading to 8,272 unique child health record consent decisions and 6,439 education record decisions.

\section{Variables Possibly Related to the Consent Outcome}

Based on the presented framework, several variables collected in the survey are included as potentially important relationships with consent (see Appendix for questions used). Respondent sociodemographic variables include: sex, ethnicity, age, employment status, educational attainment, whether they currently cohabit with a partner or not, whether they have one child or more. Respondents are identified as receiving benefits if they receive any benefit except a child benefit, which is provided to most families. 
Additional respondent factors include their risk aversion and trust levels. Variables are therefore included regarding the respondent's general inclination to take or avoid risks and the respondent's attitude towards trusting others (both on 11-point scales). Health status may also be an influence (e.g. Sakshaug et al. 2012; Sala et al. 2012) and SF-12 physical health scores are included, scaled from 0 for the lowest level of health to 100 for the highest level of health. An indicator of support for left-leaning parties support is also included. ${ }^{2}$ While parental styles may be important, the survey does not have the measures used to identify these indicators.

At the respondent's household environment-level, home ownership and monthly household income (in thousands of GBP) are included. The total number of members in the household (capped at 10 to control outliers) is included as it may indicate differences in household composition and environment. Given the noted relationship between urbanicity and consent (Korbmacher \& Schroeder 2013) and following Jenkins et al. (2006) and Sala et al. (2012), London and the southeast of England are compared to the remainder of the UK.

Survey environment variables include the number of calls to the household is included, which may indicate survey resistance (e.g. Sakshaug et al. 2012). The length of the interview not including the time for consent questions (as those who consent may take more time to read and sign forms) is used as a possible indicator of respondent-interviewer rapport (e.g. Jenkins et al. 2006). An error in the survey led to 45 cases having no interview times recorded. An indicator of whether others are present (recorded by the interviewer) during the interview is included as other may influence decisions (e.g. Sala et al. 2012).

At the interviewer level, 916 interviewers asked at least one adult for consent to link children's administrative records to their survey responses. The interviewer demographics

\footnotetext{
${ }^{2}$ Labour, Liberal-Democrat, Scottish National Party, Plaid Cymru, Green Party, SDLP, Alliance, and Sinn Fein
} 
available from the field agency include age, sex, and ethnicity. However, a large number of the interviewers refused to disclose their ethnicity (21.8\%), and so interviewer ethnicity will not be considered further. Experience as an interviewer at the research company is also included. Sex, age, and experience at the research agency are all missing for 17 interviewers, but these account for only five of the 8,272 unique consent requests examined here.

Two additional derived measures are included regarding interviewer experience with Understanding Society. One is interviewer experience with Understanding Society indicated by the number of interviews completed up to the point that a given interview is taking place. The other is the interviewer's achieved response rate in Understanding Society, used an as indicator of interviewer ability.

\section{The Youth Survey}

Interviewers also attempted to hand out paper self-administered questionnaires to all 10-15 year old household members. Verbal consent was sought from the parent or responsible adult before giving the surveys to these youths. These surveys were handed out with a plain envelope to protect confidentiality of responses. Youth questionnaires included questions about health, behaviours, school, neighbourhood, families, and other beliefs. ${ }^{3}$ Within productive households there were 6,607 youths aged 10-15 eligible for the survey; 4,895 $(74.1 \%)$ of these completed it.

Several measures are used to compare youths with and without obtained consent for data linkage. Self-reported behavioural categorical measures include: frequency arguing with mother ("hardly" or more); use the internet daily or not; having a social media account; having their own mobile phone; whether they eat $3+$ fruits and/or vegetables per day or

\footnotetext{
${ }^{3}$ Full questionnaires can be found at https://www.understandingsociety.ac.uk/documentation/mainstage/questionnaires
} 
fewer; whether they are ever bullied or not; and whether they smoke or not. The number of friends was recorded as an open-ended response where any positive number was acceptable.

The self-assessment/attitude questions include three satisfaction questions, all measured on a 7-point scale where 7 is coded most satisfied and 1 is least satisfied. These are satisfaction with school, family, and life overall. Feeling of family support is indicated by comparing those saying they feel supported by their family in most or all things to those saying they feel supported in some things or do not feel supported. Two questions are included about how youths see themselves as people. Respondents were asked to assess the level of truth on a 3-point scale ("Not True", "Somewhat True", "Certainly True") for the statements "I get a lot of headaches, stomach-aches or sickness" and "I am usually on my own. I generally play alone or keep to myself". The response options "Somewhat True" and "Certainly True" are combined to compare against those for whom the statements were assessed to have no truth. ${ }^{4}$

\section{Analysis Methods}

For bivariate analyses, differences are detected using either chi-square (for categorical data) or $\mathrm{t}$ tests (for interval-like data). Multivariate analyses estimating the effects of selected variables on consent outcomes are conducted using multilevel logistic regression. These models account for the dichotomous nature of the outcome variable (consent or not) as well as the structure of the data as respondents are nested within interviewers. Given that almost every mother gave the same consent outcome for all of their children, regardless of number, child-level variation does not appear to be related to the consent decision. Rather, there is one unique choice for nearly every mother (consent or not) for all of their children. That there is

\footnotetext{
${ }^{4}$ Chi-square tests using shows no significant differences between these two categories in consent rates.
} 
almost no within-mother variation, only one outcome is used for each mother (dropping the 37 inconsistent cases noted previously).

Random intercept models are used, with the one random effect occurring at the interviewer-level. Random intercept models also allow for the estimation of the interviewer intraclass correlations (ICC). The ICC measures the proportion of the variance in the dependent variable accounted for by the level-2 units, i.e. interviewers (Luke 2004). Initial random intercepts-only (i.e. null) models are estimated for the initial interviewer intraclass correlations (ICC) as a baseline comparison. The null models include only cases used in the full models. However, comparisons of nested multilevel models using the same categorical outcome should be made noting these are not strictly comparable (Bauer 2009; Hox 2010). The full models predict consent outcomes using respondent (mothers), household, survey environment, and interviewer measures contained in Table 1.

\section{TABLE 1 HERE}

The final column shows that for some measures, particularly for risk, trust, and party support, there is more missing data than for others. In analyses, those not in the labour force are used as the baseline to compare those employed or unemployed and those with less than a professional degree is the baseline educational category. British/Irish whites are used as the baseline ethnicity category for comparison with minority groups.

\section{Results}

\section{Consent to Link Children's Health and Education Records}

Table 2 presents the consent rates to link administrative records for mothers and their children. Only a small percentage of mothers were eligible to consent for linking their own educational records (i.e. born after 1981 and attended school in the UK), explaining the much 
smaller sample size. There is also missing data for the health records consent request for one mother, leading to the slight difference in achieved sample size.

\section{TABLE 2 HERE}

Consent rates for health records are lower than consent for education records for both mothers and children. Health records may be perceived as more private than education records; greater concerns about privacy can lead to lower consent rates (Sakshaug et al. 2012). Further, mothers consent at higher rates for themselves than for their child, with a more pronounced difference between consent rates for mother and child health records than between mother and child education records.

There are 6,439 mothers who were asked for consent to link both health and education records for at least one child. Of these mothers who responded to both requests, $88.6 \%$ gave the same consent outcome to both requests (not shown). Overall, 59.4\% of mothers said yes to both requests, $29.2 \%$ said no to both, and $11.4 \%$ said yes to one and no to the other. Among this last group who gave differing consent decisions for their children's health and education records, $9.1 \%$ said yes to education and no to health, while $2.3 \%$ said yes to health and no to education. While these respondents provided differing responses, the large majority gave the same consent outcome, suggesting that the factors influencing both decisions may be similar.

To identify these possible influencing factors, multivariate analyse are conducted using multilevel logistic regression models. The random intercepts-only (i.e. null) multilevel logistic regression models for these outcomes estimate that for children's health consents the interviewer ICC is 0.105 , while for children's education consents it is 0.159 . These moderatesized ICCs indicate that the influence of interviewers explain $10.5 \%$ of the variance for health consent outcomes and $15.9 \%$ of the variance for education consent outcomes. Including the 
variables representing the different factors outlined in the framework and presented in Table 1 into the models significantly improves fit over the respective null models for both consent outcomes (for health $\chi_{27}^{2}=153.87, \mathrm{p}<0.01$; for education $\chi_{27}^{2}=143.95, \mathrm{p}<0.01$ ). The results of the full models are presented in Table 3.

\section{TABLE 3 HERE.}

The significant effects, presented as odds ratios, are largely consistent across children's health and education consent outcomes. This consistency suggests that certain types of circumstances may explain consent decisions, rather than the specific records included in the consent request. For both consent requests, minority ethnicities generally have lower predicted odds than British or Irish whites. The only non-significant comparison group is for other ethnicities in the education model, which may be in part due to power. The estimate for this group in the education consent model is otherwise consistent in direction and magnitude with the health model. The impact of minority status is not related to being born in the UK or not; when grouping respondents based on place of birth (UK or internationally) and including this in the health consent model rather than ethnicity (not shown), no effect is found $(\mathrm{p}=0.21)$. These racial differences suggest possible biases in the obtained administrative records.

Those owning their home have lower predicted odds of consent for either children's health or education records, as is having a university degree. Taken together, there is some evidence that those with higher socioeconomic status are less likely to consent for children, again possibly introducing some bias. However, other measures of SES, such as employment status and household income show no significant impact.

Importantly, attitudinal factors relating to party support and trust in strangers are significant in predicting consent outcomes. Those supporting left-leaning political parties are 
more likely to consent to linkage of children's administrative records, as are those expressing a greater propensity to trusting strangers. These findings are similar to those found studies adults consenting for themselves in the survey setting, with those more socially-oriented more inclined to consent (e.g. Sala et al. 2012).

The survey environment also has an important impact on consent rates for linking children's administrative records. More calls required to obtain a survey completion is negatively related to consent, consistent with a survey resistance explanation (Sakshaug et al. 2012). Estimated interview length, a potential measure of interviewer-respondent rapport, is also significant in the expected direction, with longer interviews (greater rapport) related to higher odds of consent. Those who had others present during the survey are also more likely to consent to education records linkage, all else being equal. These findings contrast with Sala et al. (2012), which found no effect for the presence of others on consent.

The reasons for this effect are unclear, based on interviewer observations. If the interviewer indicated the presence of another in their observation $(n=4011)$, they were asked about what influence the other person appeared to have on the respondent. Interviewers indicated that in the large majority $(80.8 \%)$ of cases the additional other(s) had no influence at all on responses. Another $14.0 \%$ were noted as having a little influence, $3.7 \%$ having a fair amount of influence, and $1.5 \%$ having a lot of influence. If the interviewer indicated any influence at all, they were then asked to record in what way the respondent was influenced.

Of the 768 cases where any influence was recorded, the most reported form of influence was the respondent sought help from others (26.7\%), although the form of this help is not specified. The next highest reported form of influence is that others answered some survey questions for the respondent (26.6\%), then help with recall of information (e.g. dates and amounts) (19.7\%). Which questions these took place for and in what manner the help took is not recorded; however, interviewers indicated that the other(s) disapproved of 
respondents' answers in only $1.8 \%(\mathrm{n}=14)$ cases where others influenced the respondent. Of these 14 cases, only 4 consented to link children's health records and 3 consented for education records.

Moving to the interviewer-level factors, none of the interviewer characteristics have a significant effect on children's health records consent rates. Interviewer demographics, including years as interviewer, do not have a significant effect in either model. Given that only mothers are considered, the lack of significance of interviewer sex suggests no effect of female interviewer-respondent pairings on consent. The lack of an interaction varies from the finding that women respondents are more likely to consent to an interview when approached by a female interviewer (Durrant et al. 2010). The lack of interviewer effects in the children's health records model is in part reflected in the relatively minor reductions in interviewer ICC from the null to full models, acknowledging limitations in comparing ICCs across multilevel logistic models (Bauer 2009; Hox 2010). There is only a 10.5\% relative decrease in the ICC for the health consent model (i.e. 0.105-0.094/0.105).

Conversely, there are significant interviewer-level effects found for intra-survey experience and response on child education consent outcomes. More completed interviews and a higher response rate in the Understanding Society survey are related to higher probabilities of consent to link children's education records. Interviewer experience and success therefore appear to have an effect, but evidently for only some types of requests. Constraining the health model to only sample members who are also included in the education model still produces no significant effects for interviewer variables. It appears that the effect is related to specific requests rather than specific respondents. Even with these significant effects there is only an $8.8 \%$ relative decrease in the ICC for the education model. In combination with the lack of effects for the health model, there possibly are additional interviewer effects of importance that are currently not measured. 


\section{The Joint Mother-Child Consent Outcome}

The above analysis shows factors that are related to consent decisions made by mothers for their children. It may also be the goal to study the administrative records and linked survey responses for mothers and their children jointly, for example to see how health outcomes covary or generational change in outcomes. In this case, it is important that consent is obtained for both. An adult may not consent for either, consent for themselves but not their children, for their children but not themselves, or for both their children and themselves. Little research has examined this joint outcome in a systematic manner, but the current data contains consent decisions for both mothers and their children. Given the restrictions for education consent, only 154 mothers that were asked for access to their education records also had eligible school-age children at Wave 1. However, everyone was asked for health record linkage, and given the similarities found in consent for children's health and education records, joint health consent is analysed. Table 4 presents the joint outcomes for the consent to link health record requests of mothers and their children.

\section{TABLE 4 HERE}

The majority of mothers consent for both themselves and their children, with the second largest category being those who consent for neither children nor themselves. These consistent outcomes account for $88.2 \%$ of decisions; however, a sizable number of mothers consent for one health record request but not the other. Most of these inconsistencies occur where the mother consents for themselves only (8.9\%), but $2.8 \%$ consent for their children only. That more mothers consent only for themselves than those that consent for their children only contrasts with findings in Klassen et al. (2005). 
To examine the differences more deeply, multivariate analyses estimate the relationships between the various factors that may influence consent decisions and the joint health records consent outcome. One of the main goals of the analysis is to identify possible reasons why a mother consents for only one of the requests, but not both. As such, a multilevel multinomial logistic regression (random intercepts) model is estimated using consent to both requests as the baseline to which all other outcomes are compared. Therefore odds ratios greater than one suggests the effect leads to lower odds of consenting to both consent requests. The null model interviewer ICC is 0.099 , suggesting some interviewer influence. The full model uses same the independent variables in Tables 1 and 3 . The full model significantly improves fit over the null $\left(\chi_{27}^{2}=153.87, \mathrm{p}<0.01\right)$ and reduces the interviewer ICC by $12.9 \%$. Table 5 presents the results in terms of odds ratios.

\section{TABLE 5 HERE}

Beginning with results comparing those who do not consent for either request to those that consent to link both, benefit recipients are more likely to consent to both than refuse both. This finding is consistent with other studies of adults and supports the argument of reciprocity (e.g. Sakshaug et al. 2012). Like the children's records-only analyses, ethnic minority respondents are more likely to refuse both consent requests than are British or Irish whites. Those with university degrees and own their home are more likely to refuse both consent requests relative to those consenting to both. Socioeconomic status again appears to have some effect, with some evidence that higher SES respondents (having a university degree, home is owned) are less likely to consent to both requests and more likely to refuse both requests.

Those with higher reported levels of trust in strangers and those supporting leftleaning parties are more likely to consent to both requests than refuse both, suggesting that those more socially-oriented are more likely to consent to both requests than refuse both. The 
survey environment also continues to show an important effect on respondents consenting or refusing to both requests. Longer interviews are related to higher odds of consenting to both relative to refusing both, while more calls are related to higher rates of refusals to both requests than consents to both. These findings suggest the possibility that those with more rapport with their interviewer are more likely to accept both requests while harder-to-contact respondents are more likely to refuse both requests.

Examining next the case where the mother consented only for herself but not her children shows only two significant effects. Relative to British and Irish whites, mothers included in other racial and ethnic categories are significantly more likely to consent for just themselves than for both requests. The second differentiating factor is the measure of trust. Those with lower levels of trust are more likely to consent for only themselves relative to those who consent to requests for both themselves and their children. Generally it appears that trust is important in gaining consent.

Finally, however, trust does not have a significant impact differentiating those who consent for their children only and not themselves. Rather, the only significant factor is ethnicity. Minority ethnicities are significantly more likely to only consent for their children than those consenting for both themselves and their children. Across this multinomial model, these minority respondents show an increased likelihood to decline at least one of the requests compared to British and Irish. In combination with the children consent models, results suggest that minorities are significantly less likely to consent to requests for data linkage generally and in particular less likely to consent for themselves. This difference in consent rates has raised the concern about possible biases in linked records, both among mothers and children (Tate et al. 2006).

\section{The Differences Between Children Consented For or Not}


The goal of this research has been to identify factors leading to consent when asking mothers to link their children's administrative records to a nationally representative survey. Results also indicate possible biases among mothers, but do not speak to children characteristics specifically. To identify how the children consented for differ from those who were not consented for and potential biases, Table 6 compares measures considering all children of the included mothers. Health consent outcomes are considered as it was asked of everyone. The top portion of the table includes children's demographic data collected from mothers. Even if these differences were not significant in prediction of consent, differences may arise due to distributions in numbers of children. The bottom portion of the table displays responses from selected questions in the separate 10-15 year old youth survey, the only directly collected data from children under 15 in the study.

\section{TABLE 6 HERE.}

The children who were consented for are demographically different in several ways. Children who were consented for are on average older than those not consented for, albeit this difference is relatively small. A significantly smaller proportion of children consented for have a mother with a university degree than those children not consented for. The proportion of children consented for is smaller in London and the southeast of England. British/Irish whites constitute more and minorities are less of the consented for children compared to those not consented for. Based on these demographic differences, the children's records available for linkage may be biased, particularly given the possible relationships between health outcomes and demographics.

Examining the results from the 10-15 year old survey, however, suggests less difference on these possibly important measures, again noting the age restriction of the sample. The only significant differences identified in these measures both relate to internet usage. More of the children consented for access the internet daily and have a social media 
account than those not consented for. While internet usage may be correlated to health outcomes, many other measures possibly more related are not different across consent outcomes. Smoking rates, satisfaction measures, familial support, experience with bullying, and eating fruit and vegetables are do not differ between groupings. The lack of differences does not necessarily mean a lack of bias, particularly in the face of the identified demographic differences. However, these findings indicate the children consented for or not are similar in other important behaviours and attitudes.

\section{Discussion and Conclusions}

In examining consent for mothers and their children, a number of important factors were identified. First, nearly all mothers gave the same consent response for all of their children, suggesting that in this instance what are important are mother-level factors, rather than childlevel factors. Consent for health records is lower than for education records, and consent for children is lower than for their mothers. A number of mothers consented for themselves and then not their children; however, a non-trivial number of mothers consented only for their children and not themselves.

Further, minorities are less likely to consent for either their children or themselves, but are apparently more opposed to consent for themselves. That minorities are less likely to consent is consistent with other findings on children consent rates (Klassen et al. 2005; Tate et al. 2006). Another consistent finding is that greater trust in strangers and being supportive of left-leaning political parties has a consistent positive effect on the probability of consent. Understanding the differences across ethnic groups and the effect of beliefs such as these is important in studying possible respondent psychological processes in decision-making.

For example, research suggests that confidentiality and salience of the request may be important reasons why people choose to consent or not (Sala et al. 2014). Conversely, knowing that data linkage will reduce their burden does not appear to influence respondents 
(Sakshaug et al. 2013). It may be, however, that the psychological factors underlying consent for adults differs somewhat when children are involved. A parent consenting for their child will likely focus on protection from risk (Denham and Nelson 2003), and may be therefore judge risks differently. If there is a better understanding of the psychological factors leading to declining data linkage for responsible adults and children, possible question designs could be considered to confront the problem. Without fully understanding why respondents decline, design choices will be led by supposition. Given the demographic differences identified, further understanding of how these psychological factors differs across the population may also be illuminating. If such differences are found, findings may allow for question tailoring in survey design.

In addition to examining respondent effects, this article is among the first to examine the survey environment and interviewer as factors influencing consent outcomes for children. These factors are of particular importance to researchers since unlike respondent characteristics, these factors are more under researcher influence. Those harder-to-contact (and possibly more resistant to taking the survey) are more likely to refuse all consent requests. These respondents may be more uncooperative to the study generally, and feel that accepting the survey request is the extent of their willingness to participate. Improving strategies for contact, reducing survey resistance or increasing willingness to share further may be possible through interviewer strategies developed in the interviewer-respondent interaction (Groves \& Couper 1998). Similarly, the importance of rapport is possibly suggested by the significant positive effect of longer interviews on consent rates. However, surveys that are too long may frustrate interviewers and respondents alike.

Unlike the survey environment, interviewer characteristics have no clear effect on consent. Interviewer demographics (age and sex), overall experience, and intra-survey experience and response rate had no significant effect on health records consent for mothers 
or children. However, greater intra-survey experience and response rate both significantly increase the chances of consent for education records. Analyses show this is not sample composition, but rather apparently request specific. Why one consent request is apparently not affected by these interviewer success measures is unclear. The impact of interviewer traits across studies is similarly inconclusive (Sakshaug et al. 2012; Sala et al. 2012; Korbmacher \& Schroeder 2013). Further exploration of which, when, and why interviewer traits are important is needed, which can then be used in interviewer recruitment and training.

Finally, this study examined characteristics of children based on whether they were consented for or not. There are a number of important demographic differences, indicating a potential bias in in obtained records. Using direct measurement from children ages 10-15 suggest little differences across several behaviours and attitudes, except for internet usage. While the lack of differences may be somewhat encouraging to users of linked data, the best way to minimise bias is increase consent rates. The significant differences in consent across ethnicities raise other concerns when the data in the linked record are correlated with these demographics. For example, certain health conditions are more prevalent in certain ethnic populations, and the prevalence of these conditions may be underrepresented if these populations consent at lower rates. However, this study presents a framework to understand consent and results that suggest methods researchers can use to improve outcomes.

\section{References}

Bauer, D.J. (2009). A Note on Comparing the Estimates of Models for Cluster-Correlated or Longitudinal Data with Binary or Ordinal Outcomes, Psychometrika, 74, 97-105. Baumrind, D. (1991). The influence of parenting style on adolescent competence and substance use. Journal of Early Adolescence, 11, 56-95.

Cannell, C.F., Miller, P.V. \& Oksenberg, L. (1981). Research on Interviewing Techniques. In S. Leinhardt (ed.), Sociological Methodology, 389-437. San Francisco: Jossey-Bass. 
Denham, J.E. \& Nelson, R.M. (2002). Self-Determination Is Not an Appropriate Model for Understanding Parental Permission and Child Assent. Anesthesia \& Analgesia, 94:1049-1051

Dijkstra, W. (1987). Interviewing Style and Respondent Behavior: An Experimental Study of the Survey Interview. Sociological Methods \& Research, 16, 309-34.

Durrant, G. B., Groves, R. M., Staetsky, L., \& Steele, F. (2010). Effects of Interviewer Attitudes and Behaviors on Refusal in Household Surveys. Public Opinion Quarterly, $74,1-36$.

Groves, R. M. \& Couper, M.P. (1998). Nonresponse in Household Interview Surveys. New York: Wiley.

Hoberman, A. Shaikh, N. Bhatnagar, S., Haralam, M.A., Kearney, D.H., Colborn, D.K. ... \& Chesney, R.W. (2013). Factors that influence parental decisions to participate in clinical research: consenters vs nonconsenters. JAMA Pediatrics. $167,561-566$.

House, J.S. \& Wolf, S. (1978). Effects of Urban Residence on Interpersonal Trust and Helping Behavior. Journal of Personality and Social Psychology, 36, 1029-1043.

Hox, J.J. (2010). Multilevel Analysis: Techniques and Applications, $2^{\text {nd }}$ Edition, New York: Rutledge.

Jenkins, S. P., Cappellari,L., Lynn, P., Jaeckle, A., \& Sala, E. (2006). Patterns of Consent: Evidence from a General Household Survey Journal of the Royal Statistical Society (Series A) 169, 701-22.

Kawabata, Y., Alink, L.R.A., Tseng, W-L., van Ijzendoorn, M.H. \& Crick, N.R. (2011). Maternal and paternal parenting styles associated with relational aggression in children and adolescents: A conceptual analysis and meta-analytic review. Developmental Review, 31, 240-278.

Klassen, A.F., Lee, S.K., Barer, M. \& Raina, P. (2005) Linking Survey Data with Administrative Health Information Characteristics Associated with Consent from a Neonatal Intensive Care Unit Follow-up Study, Canadian Journal of Public Health, $96,151-154$

Knies, Gundi (ed.) (2014). Understanding Society -UK Household Longitudinal Study: Wave 1-4, 2009-2013, User Manual. Colchester: University of Essex.

Korbmacher, J. M., \& Schroeder M. (2013). Consent when linking survey data with 
administrative records: The role of the interviewer. Survey Research Methods, 7, 115131.

Lightfoot, D. \& Dibben, C. (2013) Approaches to linking administrative records to studies and surveys - a review. Administrative Data Liaison Service, University of St. Andrews. Retrieved from: http://www.adls.ac.uk/wp-content/uploads/Approaches-tolinking-administrative-records-to-studies-and-surveys-a-review.pdf

Luke, D. A. (2004). Multilevel Modeling Newbury Park, CA: Sage.

Lynn, P. (2009). Sample Design for Understanding Society Understanding Society Working Paper Series No. 2009 - 01, Institute for Social and Economic Research, University of Essex. Retrieved from: https://www.understandingsociety.ac.uk/files/working-papers/2009-01.pdf

McKinney, P.A., Jones, S., Parslow, R., Davey, N., Darowski, M., Chaudhry, B., ... \& Draper, E.S. (2005). A feasibility study of signed consent for the collection of patient identifiable information for a national paediatric clinical audit database. British Medical Journal, 330, 877-879

Sakshaug, J. W., \& Kreuter, F. (2012). Assessing the Magnitude of Non-Consent Biases in Linked Survey and Administrative Data. Survey Research Methods, 6, 113-122. Sakshaug, J.W., Couper, M. P., Ofstedal, M. B., \&Weir, D. (2012). Linking survey and administrative records: Mechanisms of consent. Sociological Methods \& Research, 41, 535-569.

Sakshaug, J. W., Tutz, V., \& Kreuter, F. (2013). Placement, wording and interviewers: Identifying correlates of consent to link survey and administrative data. Survey Research Methods, 7, 133-144.

Sala, E., J. Burton, \& G. Knies. (2012). Correlates of Obtaining Informed Consent to Data Linkage: Respondent, Interview, and Interviewer Characteristics. Sociological Methods \& Research 41, 414-439.

Sala E, Knies G, \& Burton J. (2014). Propensity to consent to data linkage: experimental evidence on the role of three survey design features in a UK longitudinal panel. International Journal of Social Research Methodology, 17, 455-473. 
Spera, C. (2005). A Review of the relationship among parenting practices, parenting styles, and adolescent school achievement. Educational Psychology Review, 17, $125-146$

Tait, A.R., Voepel-Lewise, T. \& Malviya, S. (2003). Participation of children in clinical research: factors that influence a parent's decision to consent. Anesthesiology, $99,819-825$

Tate, A.R., Calderwood, L. Dezateux, C., \& Joshi, H. (2006). Mother's consent to linkage of survey data with her child's birth records in a multi-ethnic national cohort study, International Journal of Epidemiology, 35, 294-298

University of Essex. (2012). Understanding Society: Waves 1-2, 2009-2011 [computer file]. 4th Edition. Colchester, Essex: UK Data Archive [distributor]. SN: 6614. 
Table 1. Mother Sample Characteristics

\begin{tabular}{|c|c|c|}
\hline & Mean/Proportion of Sample & $\mathrm{n}$ \\
\hline \multicolumn{3}{|l|}{ Respondent Characteristics } \\
\hline Receive a Benefit & 0.691 & 8220 \\
\hline Partner & 0.719 & 8271 \\
\hline Age & 36.29 & 8272 \\
\hline One Child & 0.449 & 8272 \\
\hline Two or More Children & 0.551 & 8272 \\
\hline SF-12 Physical & 52.01 & 8235 \\
\hline Risk Taking & 5.00 & 6731 \\
\hline Trust Strangers & 3.31 & 6734 \\
\hline Left-Leaning Party Supporter & 0.478 & 7447 \\
\hline Employed & 0.557 & 8272 \\
\hline Unemployed & 0.066 & 8272 \\
\hline Not in Labour Force & 0.377 & 8272 \\
\hline British/Irish White & 0.677 & 8270 \\
\hline Black & 0.096 & 8270 \\
\hline South Asian & 0.133 & 8270 \\
\hline Other Ethnicity & 0.021 & 8270 \\
\hline University Degree & 0.230 & 8268 \\
\hline Professional Degree & 0.136 & 8268 \\
\hline Less than Professional Degree & 0.644 & 8268 \\
\hline \multicolumn{3}{|l|}{ Household Characteristics } \\
\hline Household Size & 3.90 & 8272 \\
\hline Southeast/London & 0.317 & 8272 \\
\hline Monthly Household Income & 3479.03 & 8260 \\
\hline Own Home & 0.567 & 8254 \\
\hline \multicolumn{3}{|l|}{ Survey Environment } \\
\hline Number of Calls & 4.92 & 8265 \\
\hline Others Present & 0.485 & 8267 \\
\hline Interview Length in Minutes & 36.99 & 8227 \\
\hline \multicolumn{3}{|l|}{ Interviewer Characteristics } \\
\hline Interviewer-Age & 57.35 & 749 \\
\hline Interviewer-Female & 0.518 & 749 \\
\hline Years as Interviewer & 5.49 & 749 \\
\hline Number of UKHLS Interviews Completed & 77.93 & 753 \\
\hline Interviewer Response Rate & 0.608 & 753 \\
\hline
\end{tabular}


Table 2: Consent for Record Linkage for Mothers and Children, by Request

\begin{tabular}{ccccc}
\hline Request & Health Mother & Health Child & Education Mother & Education Child \\
\hline \multirow{2}{*}{$\%$ Consent } & $67.1 \%$ & $61.1 \%$ & $69.9 \%$ & $68.4 \%$ \\
& $(\mathrm{n}=8271)$ & $(\mathrm{n}=8272)$ & $(\mathrm{n}=624)$ & $(\mathrm{n}=6439)$ \\
\hline
\end{tabular}


Table 3. Odds Ratios for Children's Health and Education Records Consent Outcome

\begin{tabular}{|c|c|c|}
\hline & Health & Education \\
\hline \multicolumn{3}{|l|}{ Respondent Characteristics } \\
\hline No Benefits & 1.102 & 1.179 \\
\hline Partner & 1.011 & 1.185 \\
\hline Age & 1.002 & 1.003 \\
\hline One Child & 1.057 & 1.029 \\
\hline SF-12 Physical & 0.999 & 0.995 \\
\hline Risk Taking & 0.990 & 0.980 \\
\hline Trust in People & $1.072 *$ & $1.077 *$ \\
\hline Left-Leaning Party Supporter & $1.273^{*}$ & $1.277^{*}$ \\
\hline \multicolumn{3}{|l|}{ Employment Status (Not in Labour Force) } \\
\hline Employed & 1.063 & 1.094 \\
\hline Unemployed & 1.058 & 0.976 \\
\hline \multicolumn{3}{|l|}{ Ethnicity (British/Irish White) } \\
\hline Black & $0.603 *$ & $0.592 *$ \\
\hline South Asian & $0.773 *$ & $0.687 *$ \\
\hline Other Ethnicity & $0.530 *$ & 0.631 \\
\hline \multicolumn{3}{|l|}{ Education (Less than professional) } \\
\hline University Degree & $0.783^{*}$ & 0.824 \\
\hline Professional & 1.077 & 1.137 \\
\hline \multicolumn{3}{|l|}{ Household Environment } \\
\hline Household Size & 1.039 & 0.940 \\
\hline Southeast/London & 0.875 & 0.949 \\
\hline Household Income & 1.000 & 1.000 \\
\hline Own Home & $0.746^{*}$ & $0.720^{*}$ \\
\hline \multicolumn{3}{|l|}{ Survey Environment } \\
\hline Number of Calls & $0.967 *$ & $0.952 *$ \\
\hline Others Present & $1.131 *$ & $1.189^{*}$ \\
\hline Interview Length in Minutes & $1.012 *$ & $1.017^{*}$ \\
\hline \multicolumn{3}{|l|}{ Interviewer Characteristics } \\
\hline Interviewer-Age & 1.002 & 1.001 \\
\hline Interviewer-Female & 0.957 & 1.087 \\
\hline Years as Interviewer & 1.002 & 1.008 \\
\hline Number of UKHLS Interviews Completed & 1.001 & $1.002 *$ \\
\hline Interviewer Response Rate & 1.492 & $1.845^{*}$ \\
\hline Interviewer ICC & 0.094 & 0.145 \\
\hline$n$ Respondents & 6018 & 4705 \\
\hline$n$ Interviewers & 720 & 703 \\
\hline
\end{tabular}


Table 4: Joint Consent Decisions for Mother-Child Health Record Linkage

\begin{tabular}{ccccc}
\hline Mother-Child Health & Neither & Mother Only & Child Only & $\begin{array}{c}\text { Both Mother } \\
\text { and Child }\end{array}$ \\
\hline$\%$ Consent & $30.0 \%$ & $\begin{array}{c}8.9 \% \\
(\mathrm{n}=736)\end{array}$ & $\begin{array}{c}2.8 \% \\
(\mathrm{n}=235)\end{array}$ & $\begin{array}{c}58.2 \% \\
(\mathrm{n}=4817)\end{array}$ \\
\hline
\end{tabular}


Table 5. Odds Ratios for Joint Mother-Child Consent Outcomes

\begin{tabular}{|c|c|c|c|}
\hline & Neither & Mother Only & Child Only \\
\hline \multicolumn{4}{|l|}{ Respondent Characteristics } \\
\hline No Benefits & $0.842 *$ & 1.155 & 1.065 \\
\hline Partner & 0.981 & 1.000 & 1.053 \\
\hline Age & 1.000 & 0.992 & 1.005 \\
\hline One Child & 0.922 & 1.010 & 0.994 \\
\hline SF-12 Physical & 1.001 & 1.003 & 0.998 \\
\hline Risk Taking & 1.010 & 1.010 & 0.992 \\
\hline Trust in People & $0.925^{*}$ & $0.955^{*}$ & 1.005 \\
\hline Left-Leaning Party Supporter & $0.767 *$ & 0.858 & 1.082 \\
\hline \multicolumn{4}{|l|}{ Employment Status (Not in Labour Force) } \\
\hline Employed & 0.898 & 1.112 & 1.257 \\
\hline Unemployed & 0.879 & 1.210 & 1.560 \\
\hline \multicolumn{4}{|l|}{ Ethnicity (British/Irish White) } \\
\hline Black & $1.912 *$ & 1.199 & $2.137 *$ \\
\hline South Asian & $1.604 *$ & 0.770 & $2.801 *$ \\
\hline Other Ethnicity & $2.105^{*}$ & $2.006^{*}$ & $4.258^{*}$ \\
\hline \multicolumn{4}{|l|}{ Education (Less than professional) } \\
\hline University Degree & $1.301 *$ & 1.248 & 1.148 \\
\hline Professional & 0.913 & 0.923 & 0.792 \\
\hline \multicolumn{4}{|l|}{ Household Environment } \\
\hline Household Size & 0.949 & 0.983 & 0.974 \\
\hline Southeast/London & 1.180 & 1.109 & 1.079 \\
\hline Household Income & 1.000 & 1.000 & 1.000 \\
\hline Own Home & $1.324 *$ & $1.428 *$ & 1.246 \\
\hline \multicolumn{4}{|l|}{ Survey Environment } \\
\hline Number of Calls & $1.047^{*}$ & 1.005 & 1.022 \\
\hline Others Present & 0.886 & 0.931 & 1.254 \\
\hline Interview Length in Minutes & $0.987 *$ & 0.991 & 0.993 \\
\hline \multicolumn{4}{|l|}{ Interviewer Characteristics } \\
\hline Interviewer-Age & 0.999 & 1.002 & 1.006 \\
\hline Interviewer-Female & 1.072 & 1.057 & 1.308 \\
\hline Years as Interviewer & 0.992 & 1.005 & 0.976 \\
\hline Number of UKHLS Interviews Completed & 0.999 & 0.999 & 1.002 \\
\hline Interviewer Response Rate & 0.671 & 0.581 & 0.632 \\
\hline Interviewer ICC & & 0.086 & \\
\hline$n$ Respondents & & 6018 & \\
\hline$n$ Interviewers & & 720 & \\
\hline
\end{tabular}


Table 6. Children Characteristics, by Consent Outcome

\begin{tabular}{|c|c|c|c|}
\hline & $\begin{array}{l}\text { Consent } \\
(\mathrm{n}=8791)\end{array}$ & $\begin{array}{c}\text { No Consent } \\
(\mathrm{n}=5683)\end{array}$ & Difference \\
\hline \multicolumn{4}{|l|}{ Demographics, All Children } \\
\hline Female & 0.486 & 0.494 & -0.008 \\
\hline Age & 7.37 & 7.19 & $0.018 *$ \\
\hline Monthly Household Income & 3449.42 & 3509.69 & -60.27 \\
\hline Only Child & 0.279 & 0.271 & 0.008 \\
\hline Mother Has University Degree & 0.205 & 0.241 & $-0.036^{*}$ \\
\hline Southeast/London & 0.289 & 0.378 & $-0.089 *$ \\
\hline British/Irish White & 0.702 & 0.570 & $0.132 *$ \\
\hline Black & 0.071 & 0.121 & $-0.050 *$ \\
\hline South Asian & 0.140 & 0.188 & $-0.048 *$ \\
\hline \multirow[t]{2}{*}{ Other Ethnicity } & 0.016 & 0.028 & $-0.012 *$ \\
\hline & $\begin{array}{c}\text { Consent } \\
(\mathrm{n}=2772)\end{array}$ & $\begin{array}{c}\text { No Consent } \\
(n=1311)\end{array}$ & Difference \\
\hline \multicolumn{4}{|l|}{ 10-15 Year Old Survey } \\
\hline Hardly Argue w/Mother & 0.466 & 0.473 & -0.007 \\
\hline Use Internet Daily & 0.553 & 0.500 & $0.053 *$ \\
\hline Has a Social Media Account & 0.706 & 0.665 & $0.041^{*}$ \\
\hline Smoke & 0.062 & 0.056 & 0.006 \\
\hline Have Own Mobile Phone & 0.846 & 0.822 & 0.024 \\
\hline Ever Bullied & 0.197 & 0.206 & -0.009 \\
\hline 3+ Plus Fruit/Veg Per Day & 0.547 & 0.552 & 0.005 \\
\hline Number of Friends & 7.50 & 7.38 & 0.12 \\
\hline Family Satisfaction (7-Point Scale) & 6.47 & 6.42 & 0.05 \\
\hline School Satisfaction (7-Point Scale) & 5.39 & 5.41 & -0.02 \\
\hline Life Satisfaction (7-Point Scale) & 5.90 & 5.92 & -0.02 \\
\hline True Unwell A Lot & 0.397 & 0.403 & -0.006 \\
\hline True Usually On Their Own & 0.337 & 0.343 & -0.006 \\
\hline Family Support Mostly/Always & 0.788 & 0.796 & -0.008 \\
\hline
\end{tabular}

\section{Appendix: Measures Used}

\section{Health Records Linkage}

Finally, we would like to add some information from administrative health records to the answers you have given. This leaflet gives you information about what we would like to do. Please read it, ask me any questions and sign the form if you are happy for us to do this. 
We would also like to add further information on your child's health and use of health services. Could you read through this form and sign it if you wish to give permission.

\section{Education Record Linkage}

We would also like to add information from your education records. Here is a permission form and information leaflet. Please read this, ask me any questions and sign the form if you are happy for us to do this.

\section{Child Education Record Linkage}

We would also like to add further information on your child's education. Here is a permission form and information leaflet. Please read this, ask me any questions, and sign the form if you wish to give permission.

\section{Independent variables}

UK Born $=1$ if born in UK, 0 if born anywhere else

Receive a benefit = 1 if reported obtaining any of a list of benefits except child benefit, 0 if no or only child benefit received

Partner $=1$ if reported currently cohabitating with a spouse/partner, 0 if not currently cohabitating

Age $=$ Continuous measure of age, range 16-98

One Child $=1$ if mother of one child, 0 if mother of 2 or more children

SF-12 Physical $=$ SF-12 Physical Component Summary (PCS). This measure converts valid answers to the origin questions into a single physical functioning score, resulting in a continuous scale with a range of 0 (low functioning) to 100 (high functioning).

Risk Taking = "Are you generally a person who is fully prepared to take risks or do you try to avoid taking risks?" $(0=$ Avoid Taking Risks, $10=$ Fully prepared to take risks $)$

Trust in People $=$ "Are you generally a person who is fully prepared to take risks in trusting strangers or do you try to avoid taking such risks?" ( $0=$ Avoid taking risks in trusting strangers, $10=$ Fully prepared to take risks in trusting strangers)

Employed $=1$ if employed (full or part-time), 0 otherwise

Unemployed $=1$ if indicated unemployed but in labour force, 0 otherwise

British/Irish White $=1$ if white from Great Britain or Ireland, 0 otherwise

Black $=1$ if Mixed African, Mixed Caribbean, African, Caribbean, or Any other black background, 0 otherwise

South Asian = 1 if Indian, Pakistani, Bangladeshi, 0 otherwise

Other Ethnicity =1 if not classified as British/Irish White, Black, or South Asian, 0 otherwise 
College Degree $=1$ if has University Higher Degree (e.g. MSc, PhD), First degree level qualification including foundation degrees, graduate membership of a professional Institute, PGCE, 0 otherwise

Professional = 1 if Diploma in higher education, Teaching qualification (excluding PGCE), Nursing or other medical qualification, HNC/HND, 0 otherwise

Left-leaning $=1$ if favours Labour, Liberal Democrat, Scottish National Party, Plaid Cymru , Green Party, SDLP, Alliance Party, Sinn Fein, 0 otherwise

Household Size $=$ number of members living in household, capped at 10

Southeast/London $=1$ if household in southeast of England or London, 0 otherwise

Household income $=$ Total reported household income, in thousands of GBP.

Own home $=1$ if home is owned by household, 0 if not owned

Number of calls $=$ number of calls to household until survey achieved

Others present $=1$ if anyone else present during interview, 0 if no one else

Interviewer length $=$ length of interview in minutes, not including consent module

Interviewer age $=$ Continuous measure of interviewer age, range 23-82

Interviewer female $=1$ if interviewer is female, 0 if male

Years as interviewer $=$ number of years as interviewer at research company

Number of UKHLS interviews completed = number of interviews, prior to the current one, that the interviewer has completed in the current survey

Interviewer response rate $=$ proportion of successfully completed surveys of total outcomes (successfully completed surveys plus refusals and noncontacts at eligible households)

\section{Youth Survey Measures}

Hardly Argue w/Mother = 1 if answer "Hardly ever" to "Most children have occasional quarrels with their parents. How often do you quarrel with your mother?". 0 if respond "Most days", "More than once a week", or "Less than once a week"

Use Internet Daily $=1$ if indicates they use the internet daily, including for games, 0 if for any frequency less than daily

Has Social Media Account $=1$ if yes they belong to " to a social web-site such as Bebo, Facebook or MySpace", 0 if not

Smoke $=1$ if ever smoke cigarettes, 0 if not 
Have Own Mobile Phone = 1 if yes has own personal mobile phone, 0 if not

Ever Bullied = 1 if they indicate any amount of bullying - "Not much (1-3 times in last 6 months)", "Quite a lot (more than 4 times in last 6 months)" or "A lot (a few times every week)" to the question "How often do you get physically bullied at school, for example getting pushed around, hit or threatened, or having belongings stolen", 0 if responded "Never"

$3+$ Plus Fruit/Veg Per Day $=1$ if selected " 5 or more portions" or " $3-4$ portions" to question "How many portions of fresh fruit or vegetables do you eat on a typical day?", 0 is responded " $1-2$ portions" or "None"

Number of Friends = Numeric response to "How many close friends do you have - friends you could talk to if you were in some kind of trouble?"

Satisfaction questions $=7$ if selected "completely happy", 1 if selected completed "not at all happy"

True Unwell A Lot= 1 if "somewhat true" or "certainly true" that "I get a lot of headaches, stomach-aches or sickness"

True Usually On Their Own = 1 if "somewhat true" or "certainly true" that "I am usually on my own. I generally play alone or keep to myself"

Family Support Mostly/Always = 1 if responded "I feel supported by my family in most or all of the things I do" to question "Do you feel supported by your family, that is the people who live with you?", 0 if "I feel supported by my family in some of the things I do" or "I do not feel supported by my family in the things I do 